\title{
A prediction rule for severe adverse events in all inpatients with community-acquired pneumonia: a multicenter observational study
}

\author{
Toshihiro Sakakibara' ${ }^{1}$, Yuichiro Shindo ${ }^{1 *}$, Daisuke Kobayashi ${ }^{2}$, Masahiro Sano 1,3, Junya Okumura 1,4, \\ Yasushi Murakami ${ }^{1}$, Kunihiko Takahashi ${ }^{5,6}$, Shigeyuki Matsui ${ }^{5}$, Tetsuya Yagi ${ }^{7}$, Hideo Saka ${ }^{8,9}$ and \\ Yoshinori Hasegawa ${ }^{1,9}$
}

\begin{abstract}
Background: Prediction of inpatients with community-acquired pneumonia (CAP) at high risk for severe adverse events (SAEs) requiring higher-intensity treatment is critical. However, evidence regarding prediction rules applicable to all patients with CAP including those with healthcare-associated pneumonia (HCAP) is limited. The objective of this study is to develop and validate a new prediction system for SAEs in inpatients with CAP.
\end{abstract}

Methods: Logistic regression analysis was performed in 1334 inpatients of a prospective multicenter study to develop a multivariate model predicting SAEs (death, requirement of mechanical ventilation, and vasopressor support within 30 days after diagnosis). The developed ALL-COP-SCORE rule based on the multivariate model was validated in 643 inpatients in another prospective multicenter study.

Results: The ALL-COP SCORE rule included albumin ( $<2 \mathrm{~g} / \mathrm{dL}$, 2 points; $2-3 \mathrm{~g} / \mathrm{dL}, 1$ point), white blood cell $(<4000$ cells/ $\mu \mathrm{L}, 3$ points), chronic lung disease (1 point), confusion (2 points), $\mathrm{PaO}_{2} / \mathrm{F}_{1} \mathrm{O}_{2}$ ratio $(<200 \mathrm{mmHg}, 3$ points; 200-300 mmHg, 1 point), potassium ( $\geq 5.0 \mathrm{mEq} / \mathrm{L}, 2$ points), arterial $\mathrm{pH}(<7.35,2$ points), systolic blood pressure ( $<90 \mathrm{mmHg}, 2$ points), $\mathrm{PaCO}_{2}$ (> $45 \mathrm{mmHg}, 2$ points), $\mathrm{HCO}_{3}{ }^{-}(<20 \mathrm{mmol} / \mathrm{L}, 1$ point), respiratory rate ( $\geq 30$ breaths/ min, 1 point), pleural effusion (1 point), and extent of chest radiographical infiltration in unilateral lung (> 2/3, 2 points; $1 / 2-2 / 3,1$ point). Patients with $4-5,6-7$, and $\geq 8$ points had $17 \%, 35 \%$, and $52 \%$ increase in the probability of SAEs, respectively, whereas the probability of SAEs was $3 \%$ in patients with $\leq 3$ points. The ALL-COP SCORE rule exhibited a higher area under the receiver operating characteristic curve (0.85) compared with the other predictive models, and an ALL-COP SCORE threshold of $\geq 4$ points exhibited $92 \%$ sensitivity and $60 \%$ specificity.

Conclusions: ALL-COP SCORE rule can be useful to predict SAEs and aid in decision-making on treatment intensity for all inpatients with CAP including those with HCAP. Higher-intensity treatment should be considered in patients with CAP and an ALL-COP SCORE threshold of $\geq 4$ points.

Trial registration: This study was registered with the University Medical Information Network in Japan, registration numbers UMIN000003306 and UMIN000009837.

Keywords: Severe pneumonia, Severity, Mortality, Healthcare-associated pneumonia, Prediction score

*Correspondence: yshindo@med.nagoya-u.ac.jp

1 Department of Respiratory Medicine, Nagoya University Graduate

School of Medicine, 65 Tsurumai-cho, Showa-ku, Nagoya 466-8550, Japan

Full list of author information is available at the end of the article

\section{Background}

Site-of-care decision according to disease severity is one of the most critical steps in the management of pneumonia [1]. Several established prediction models have been 
developed to identify patients with community-acquired pneumonia (CAP) who are at low risk for death and can be treated in an outpatient setting. The representative models include the Pneumonia Severity Index (PSI) and the CURB-65 (confusion, blood urea nitrogen $>7 \mathrm{mmol} / \mathrm{L}$ $[20 \mathrm{mg} / \mathrm{dL}]$, respiratory rate $\geq 30 / \mathrm{min}$, low blood pressure [diastolic blood pressure $\leq 60 \mathrm{~mm} \mathrm{Hg}$ or systolic blood pressure $<90 \mathrm{~mm} \mathrm{Hg}$ ], and age $\geq 65$ years) $[2,3]$.

Identification of patients at high risk for severe adverse events (SAEs) at the time of pneumonia diagnosis is also crucial. These risk assessments aid physicians in determining patients who require higher-intensity treatment [4]. Some of the prediction models proposed for the identification of these patients include the 2007 Infectious Diseases Society of America (IDSA)/American Thoracic Society (ATS) criteria [1], the España SCAP rule [5], and the SMART-COP [6]. However, approaches to identify and assess patients who might need more intense treatment compared to those at low risk for SAEs remain a debatable issue [7-9]. Furthermore, although the management of patients with CAP and those with healthcareassociated pneumonia (HCAP) have been considered as the same entity in the 2019 ATS/IDSA CAP guidelines [4, 10], evidence is limited regarding prediction models that can be applicable to all patients with CAP including those with HCAP to identify those who require higher-intensity treatment at the time of pneumonia diagnosis.

Therefore, we aimed to develop and validate a prediction tool for the identification of all patients with CAP who are at high risk for SAEs using two different cohort datasets that were prospectively collected.

\section{Methods}

\section{Study design and setting}

This study was performed using datasets of two different prospective observational studies [11, 12]. A prediction model was developed using a larger dataset from an observational study (derivation cohort), which was performed at ten medical institutions in Japan (one 1000-bed university hospital and nine major community hospitals, each equipped with more than 500 beds) between March and December 2010 [11, 13, 14]. The prediction model was validated using a dataset from another observational study (validation cohort), which was performed at four medical institutions between April 2013 and March 2014. These four institutions participated in the first study for the derivation cohort as well [12]. There were no overlapping cases between the derivation and validation cohorts.

The study protocol adhered to the Declaration of Helsinki and the Japanese Ethics Guidelines for Epidemiological Studies. The study was approved by the ethics committee of Nagoya University and respective institutional review boards of the participating institutions.
Informed consent of the participants was waived, but the opt-out method was adopted according to the ethics guidelines.

\section{Patients}

Details on pneumonia definitions and categories, inclusion and exclusion criteria, definitions of variables, procedures, and data collection have been described elsewhere [11,12] and can be found in the Additional file 1 . Briefly, patients aged 20 years or older who developed pneumonia outside of a hospital and needed inpatient treatment were enrolled. Definitions of pneumonia categories were in accordance with international guidelines $[1,15]$. The study included adult patients with CAP including those with HCAP. Outpatients and patients with hospital-acquired and ventilator-associated pneumonia were excluded.

\section{Endpoints}

The primary study endpoint was SAEs, which were composite and included all-cause death and requirement of mechanical ventilation (MV) or vasopressor support (VS) within 30 days after pneumonia diagnosis. MV included invasive and noninvasive MV. Secondary endpoints were individual components of the primary endpoint and intensive care unit (ICU) admission within 30 days after the pneumonia diagnosis.

\section{Model development}

Patient data without missing values were used for model development (complete-case analysis). A total of 33 candidate variables potentially associated with SAEs, except type of pneumonia, were identified from the literature review and are shown in Additional file 2 and Table 1 [1-3, 5, 6, 16-18]. Categorization of continuous variables and cutoff values were determined with reference to previous studies [1-3, 5, 6, 16-18], clinical significance, and data distribution of each variable. First, univariate logistic regression analysis was performed to assess the effects of candidate variables on SAEs. Next, multivariate logistic regression analysis was performed using all 33 candidate variables. A forward stepwise selection procedure was used with the inclusion of variables with a $p$ value of less than 0.1. $\beta$-coefficients, odds ratios (ORs), and the corresponding 95\% confidence intervals (CIs) were calculated. A simple prediction scoring system was developed based on the multivariate logistic regression model by rounding $\beta$-coefficients. The frequencies of SAEs were calculated by points. Receiver operating characteristic (ROC) curves of the multivariate logistic regression model and the simple prediction scoring system were assessed. The point with higher sensitivity was preferred when determining the threshold of the simple prediction scoring 
Table 1 Patient characteristics and clinical outcomes

\begin{tabular}{|c|c|c|}
\hline Variables & $\begin{array}{l}\text { Derivation cohort } \\
(n=1334)\end{array}$ & $\begin{array}{l}\text { Validation cohort } \\
(n=643)\end{array}$ \\
\hline \multicolumn{3}{|l|}{ Age, years } \\
\hline$<65$ & $250(18.7)$ & $106(16.5)$ \\
\hline $65-79$ & $528(39.6)$ & $269(41.8)$ \\
\hline$\geq 80$ & $556(41.7)$ & $268(41.7)$ \\
\hline Sex, female & $463(34.7)$ & $208(32.3)$ \\
\hline \multicolumn{3}{|l|}{ Pneumonia type } \\
\hline $\mathrm{CAP}^{+}$ & $836(62.7)$ & $437(68.0)$ \\
\hline $\mathrm{HCAP}^{\ddagger}$ & $498(37.3)$ & $206(32.0)$ \\
\hline Nursing home resident & $216(16.2)$ & $108(16.8)$ \\
\hline Nonambulatory status & $327(24.5)$ & $133(20.7)$ \\
\hline Nonambulatory status or age $\geq 80$ years & $683(51.2)$ & $301(46.8)$ \\
\hline Heavy alcohol use $\mathrm{s}^{\S}$ & $40(3.0)$ & $19(3.0)$ \\
\hline \multicolumn{3}{|l|}{ Comorbidities } \\
\hline Neoplastic diseases & $191(14.3)$ & $93(14.5)$ \\
\hline Congestive heart failure & $177(13.3)$ & $112(17.4)$ \\
\hline Chronic liver diseases & $51(3.8)$ & $16(2.5)$ \\
\hline Cerebrovascular diseases & $291(21.8)$ & $100(15.6)$ \\
\hline Diabetes & $251(18.8)$ & $110(17.1)$ \\
\hline Immunosuppression" & $118(8.8)$ & $58(9.0)$ \\
\hline Chronic renal diseases & $108(8.1)$ & $47(7.3)$ \\
\hline Chronic lung diseases & $451(33.8)$ & $232(36.1)$ \\
\hline \multicolumn{3}{|l|}{ Physical examination } \\
\hline Altered mental status (confusion) & $266(19.9)$ & $142(22.1)$ \\
\hline Pulse rate $\geq 125 / \mathrm{min}$ & $135(10.1)$ & $72(11.2)$ \\
\hline Body temperature $<36.0^{\circ} \mathrm{C}$ & $42(3.1)$ & $10(1.6)$ \\
\hline Systolic blood pressure $<90 \mathrm{mmHg}$ & $74(5.5)$ & $31(4.8)$ \\
\hline Respiratory rate $\geq 30 / \mathrm{min}$ & $311(23.3)$ & $146(22.7)$ \\
\hline \multicolumn{3}{|l|}{ Laboratory test } \\
\hline Blood urea nitrogen $\geq 30 \mathrm{mg} / \mathrm{dL}$ & $298(22.3)$ & $132(20.5)$ \\
\hline \multicolumn{3}{|l|}{ Glucose, mg/dL } \\
\hline$<70$ & $19(1.4)$ & $9(1.4)$ \\
\hline$\geq 250$ & $97(7.3)$ & $39(6.1)$ \\
\hline \multicolumn{3}{|l|}{ Albumin, $\mathrm{g} / \mathrm{dL}$} \\
\hline$<2.0$ & $35(2.6)$ & $20(3.1)$ \\
\hline $2.0-3.0$ & $416(31.2)$ & $175(27.2)$ \\
\hline \multicolumn{3}{|l|}{ Sodium, mEq/L } \\
\hline$<130$ & $91(6.8)$ & $61(9.5)$ \\
\hline$\geq 146$ & $49(3.7)$ & $14(2.2)$ \\
\hline Potassium $\geq 5.0 \mathrm{mEq} / \mathrm{L}$ & $122(9.1)$ & $38(5.9)$ \\
\hline Total bilirubin $\geq 2.0 \mathrm{mg} / \mathrm{dL}$ & $59(4.4)$ & $19(3.0)$ \\
\hline White blood cell count $<4000$ cells $/ \mu \mathrm{L}$ & $44(3.3)$ & $19(3.0)$ \\
\hline Hematocrit $<30 \%$ & $192(14.4)$ & $72(11.2)$ \\
\hline Platelet count $<100000$ cells $/ \mu \mathrm{L}$ & $58(4.3)$ & $23(3.6)$ \\
\hline \multicolumn{3}{|l|}{ Blood gas analysis } \\
\hline \multicolumn{3}{|l|}{$\mathrm{PaO}_{2} / \mathrm{F}_{1} \mathrm{O}_{2}$ ratio } \\
\hline$\leq 100 \mathrm{mmHg}$ & $111(8.3)$ & $39(6.1)$ \\
\hline $100-200 \mathrm{mmHg}$ & $209(15.7)$ & $90(14.0)$ \\
\hline 200-300 mmHg & $482(36.1)$ & $261(40.6)$ \\
\hline
\end{tabular}


Table 1 (continued)

\begin{tabular}{|c|c|c|}
\hline Variables & $\begin{array}{l}\text { Derivation cohort } \\
(n=1334)\end{array}$ & $\begin{array}{l}\text { Validation cohort } \\
(n=643)\end{array}$ \\
\hline Arterial $\mathrm{pH}<7.35$ & $148(11.1)$ & $58(9.0)$ \\
\hline $\mathrm{PaCO}_{2}>45 \mathrm{mmHg}$ & $212(15.9)$ & $77(12.0)$ \\
\hline $\mathrm{HCO}_{3}{ }^{-}<20 \mathrm{mmol} / \mathrm{L}$ & $170(12.7)$ & $63(9.8)$ \\
\hline \multicolumn{3}{|l|}{ Radiological findings } \\
\hline Pleural effusion & $324(24.3)$ & $133(20.7)$ \\
\hline \multicolumn{3}{|l|}{ Extent of total infiltration } \\
\hline 1/3-2/3 of unilateral lung & $415(31.1)$ & $208(32.3)$ \\
\hline$>2 / 3$ of unilateral lung & $268(20.1)$ & $143(22.2)$ \\
\hline \multicolumn{3}{|l|}{ Outcomes } \\
\hline Severe adverse events** & $277(20.8)$ & $120(18.7)$ \\
\hline 30-Day mortality & $163(12.2)$ & $60(9.3)$ \\
\hline Requirement of MV or VS within 30 days $^{\dagger \dagger}$ & $154(11.5)$ & $74(11.5)$ \\
\hline Requirement of MV within 30 days & $130(9.7)$ & $64(10.0)$ \\
\hline Requirement of VS within 30 days & $83(6.2)$ & $28(4.4)$ \\
\hline ICU admission within 30 days & $99(7.4)$ & $66(10.3)$ \\
\hline
\end{tabular}

* Data are presented as no (\%)

Definition of abbreviations: CAP, community-acquired pneumonia; HCAP, healthcare-associated pneumonia; MV, mechanical ventilation; VS, vasopressor support; ICU, intensive care unit

${ }^{\dagger}$ CAP excluding HCAP was defined as pneumonia that did not match the criteria for hospital-acquired pneumonia (pneumonia occurring $48 \mathrm{~h}$ or more after hospital admission) or HCAP

${ }^{\ddagger}$ HCAP was defined as pneumonia co-occurring with any of the following conditions: hospitalization for 2 days or more during the preceding 90 days, residence in a nursing home or extended care facility, at-home intravenous therapy (including antibiotics and chemotherapy), chronic dialysis (including hemodialysis and peritoneal dialysis) during the preceding 30 days, or home wound care during the preceding 30 days

${ }^{\S}$ Heavy alcohol use was defined as a mean daily alcohol intake of $120 \mathrm{~g} /$ day

"Immunosuppression included any immunosuppressive diseases, such as congenital or acquired immunodeficiency, hematologic diseases, asplenia and neutropenia $(<1000$ cells/ $\mu \mathrm{L})$, treatment with immunosuppressive agents, chemotherapy within the previous 30 days, and corticosteroids in daily doses of at least $10 \mathrm{mg} /$ day prednisone equivalent for more than 2 weeks

** Severe adverse events included death and requirement of mechanical ventilation (invasive or noninvasive) or vasopressor support within 30 days after pneumonia diagnosis

${ }^{\dagger \dagger} 38$ patients in the derivation cohort and 14 patients in the validation cohort required invasive MV or VS at admission

system. We also considered that the possible acceptable specificity was at least $60 \%$ (between 60 and 70\%) according to previous studies on the España SCAP rule and SMART-COP [4-6]. In addition, the ROC curve and calculated Youden's index were utilized to determine the threshold [19].

\section{Model performance and validation}

Sensitivity, specificity, positive predictive value (PPV), negative predictive value (NPV), area under the ROC curve (AUROC), and corresponding 95\% CIs were calculated to assess model performance. Positive likelihood ratio (PLR) and negative likelihood ratio (NLR) were also calculated. These values were compared among prediction models using the validation cohort. Validation analyses were performed in patients without missing values.

\section{Severity assessment tools for comparisons}

The PSI [2], CURB-65 [3], 2007 IDSA/ATS criteria [1], simplified 2007 IDSA/ATS minor criteria [20],
SMART-COP [6], and España SCAP rule [5] were assessed for comparisons. For each prediction method, the diagnostic accuracy was assessed using the following thresholds reported in the original articles on these tools: PSI, $\geq$ class IV; CURB- $65, \geq 3$ points; España SCAP rule, $\geq 10$ points; SMART-COP, $\geq 3$ points; 2007 IDSA/ ATS criteria (minor criteria), $\geq 3$ factors [21]; and simplified 2007 IDSA/ATS minor criteria, $\geq 3$ factors [20]. During calculations for the 2007 IDSA/ATS criteria, simplified 2007 IDSA/ATS minor criteria, SMART-COP, and España SCAP rule, multilobar radiological infiltration was substituted by bilateral or chest radiographical infiltration extending to more than $2 / 3$ of the unilateral lung.

\section{Subgroup analyses}

Subgroup analyses were performed in patients without potential treatment restrictions, those with CAP (excluding HCAP) or HCAP, those without invasive MV/VS at admission, and those without immunosuppression. Patients without potential treatment restriction were 


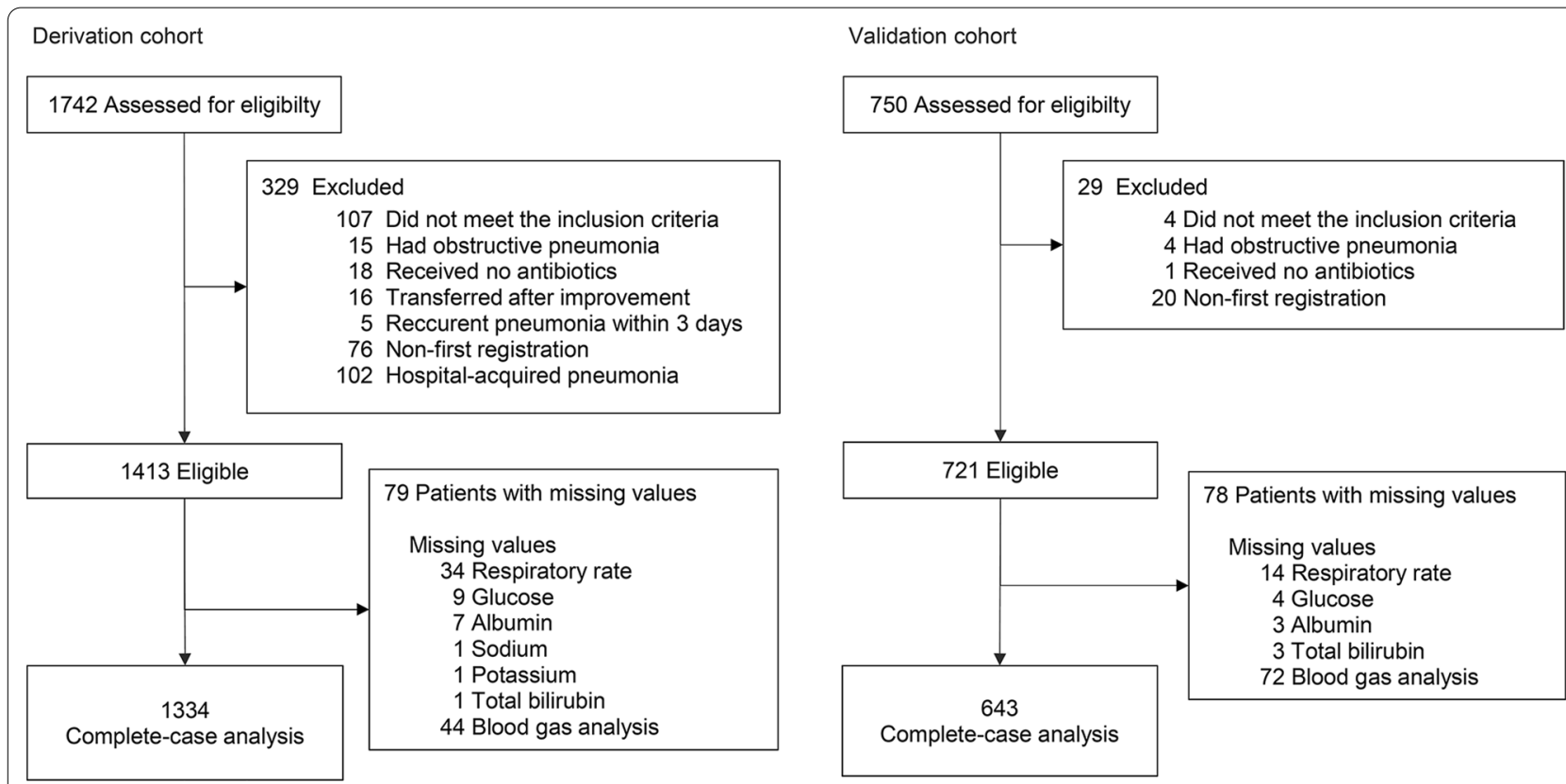

Fig. 1 Patient flowchart in the derivation and validation cohorts. Model development and validation were performed in patients without missing values (complete-case analysis)

defined as ambulatory patients under 80 years. Those with potential treatment restrictions were defined as those aged 80 years or older or any patient with nonambulatory status [22]. Invasive MV/VS at admission corresponded to the major criteria of the 2007 IDSA/ATS criteria [1]. Immunosuppression included any immunosuppressive diseases, such as congenital or acquired immunodeficiency, hematologic diseases, asplenia and neutropenia $(<1000$ cells $/ \mu \mathrm{L})$, treatment with immunosuppressive agents, chemotherapy within the previous 30 days, and use of corticosteroids in daily doses of at least $10 \mathrm{mg} /$ day prednisone equivalent for more than 2 weeks [11].

\section{Statistical analysis}

Categorical data were summarized as frequencies presented as percentages. All tests were two-tailed. Statistical data were analyzed using SPSS Statistics (version 25; IBM, Armonk, NY, USA) unless otherwise indicated. Prism (version 7.04; GraphPad, San Diego, CA, USA) was used to calculate $95 \%$ CIs for sensitivity, specificity, PPV, and NPV. PLR and NLR were calculated using EZR (version 1.54; Saitama Medical Center, Jichi Medical University, Saitama, Japan).

\section{Results}

\section{Characteristics of the cohorts}

A total of 1413 patients were eligible in the derivation cohort, and 721 patients were included in the validation cohort. After excluding patients with missing data, the derivation and validation cohorts comprised 1334 and 643 patients, respectively (Fig. 1). The baseline patient characteristics were closely comparable between the derivation and validation cohorts (Table 1). The percentages of patients aged 80 years or older were identical in both the derivation and validation cohorts (42\%). The percentages of patients with hyperpotassemia $(K \geq 5.0 \mathrm{mEq} / \mathrm{L})$ and hypercapnia $\left(\mathrm{PaCO}_{2}>45 \mathrm{mmHg}\right)$ were higher in the derivation cohort than in the validation one. The incidence proportions of SAEs in the derivation and validation cohorts were $20.8 \%$ and $18.7 \%$, respectively (Table 1 ).

\section{Prediction model development for SAEs in the derivation cohort}

The results of the univariate analysis between 33 candidate variables and SAEs are shown in Additional file 2. As a result of the multivariate logistic regression analysis with forward stepwise selection, the prediction model for SAEs comprised 13 significant variables (Table 2). By rounding the $\beta$-coefficients of these variables, a simple scoring system was developed, named ALL-COP SCORE rule (Table 2, Fig. 2), which included the following variables: serum albumin level $(<2 \mathrm{~g} / \mathrm{dL}, 2$ points; $2-3 \mathrm{~g} /$ $\mathrm{dL}, 1$ point); leukopenia (white blood cell count; $<4000$ cells/ $\mu \mathrm{L}, 3$ points); chronic lung disease (1 point); confusion (2 points); $\mathrm{Pa} \underline{O}_{2} / \mathrm{F}_{\mathrm{I}} \mathrm{O}_{2}$ ratio $(<200 \mathrm{mmHg}, 3$ points; 200-300 $\mathrm{mmHg}, 1$ point); potassium level $(\geq 5.0 \mathrm{mEq} / \mathrm{L}$, 2 points); arterial $\mathrm{pH}(<7.35,2$ points); systolic blood 
Table 2 Multivariate analysis for severe adverse events in the derivation cohort

\begin{tabular}{|c|c|c|c|c|c|}
\hline \multirow[t]{2}{*}{ Variables } & \multicolumn{2}{|c|}{ Severe adverse events* } & \multicolumn{2}{|c|}{ Multivariate analysis } & \multirow{2}{*}{$\begin{array}{l}\text { Points } \\
\text { assigned }^{\dagger}\end{array}$} \\
\hline & Yes $(n=277)$ & No $(n=1057)$ & $\beta$-coefficient & OR $(95 \% \mathrm{Cl})$ & \\
\hline Intercept & & -3.82 & & & \\
\hline \multicolumn{6}{|l|}{ Chronic lung diseases } \\
\hline No & 166 & 717 & 0 & 1 (Ref) & \\
\hline Yes & 111 & 340 & 0.31 & $1.36(0.97-1.93)$ & 1 \\
\hline \multicolumn{6}{|l|}{ Altered mental status } \\
\hline No & 158 & 910 & 0 & 1 (Ref) & \\
\hline Yes & 119 & 147 & 0.76 & $2.14(1.48-3.08)$ & 2 \\
\hline \multicolumn{6}{|l|}{ Systolic blood pressure, $\mathrm{mmHg}$} \\
\hline$\geq 90$ & 247 & 1013 & 0 & 1 (Ref) & \\
\hline$<90$ & 30 & 44 & 0.61 & $1.85(1.02-3.35)$ & 2 \\
\hline \multicolumn{6}{|l|}{ Respiratory rate, /min } \\
\hline$<30$ & 169 & 854 & 0 & 1 (Ref) & \\
\hline$\geq 30$ & 108 & 203 & 0.30 & $1.35(0.95-1.92)$ & 1 \\
\hline \multicolumn{6}{|l|}{ Albumin, $g / d L$} \\
\hline$\geq 3.0$ & 134 & 749 & 0 & 1 (Ref) & \\
\hline $2.0-3.0$ & 128 & 288 & 0.44 & $1.55(1.11-2.19)$ & 1 \\
\hline$<2.0$ & 15 & 20 & 0.74 & $2.09(0.90-4.86)$ & 2 \\
\hline \multicolumn{6}{|l|}{ Potassium, mEq/L } \\
\hline$<5.0$ & 226 & 986 & 0 & 1 (Ref) & \\
\hline$\geq 5.0$ & 51 & 71 & 0.80 & $2.22(1.39-3.56)$ & 2 \\
\hline \multicolumn{6}{|c|}{ White blood cell count, cells/ $\mu \mathrm{L}$} \\
\hline$\geq 4000$ & 254 & 1036 & 0 & 1 (Ref) & \\
\hline$<4000$ & 23 & 21 & 1.24 & $3.45(1.68-7.11)$ & 3 \\
\hline \multicolumn{6}{|l|}{$\mathrm{PaO}_{2} / \mathrm{F}_{1} \mathrm{O}_{2}$ ratio, $\mathrm{mmHg}$} \\
\hline$>300$ & 47 & 485 & 0 & 1 (Ref) & \\
\hline $200-300$ & 85 & 397 & 0.52 & $1.68(1.10-2.55)$ & 1 \\
\hline $100-200$ & 82 & 127 & 1.02 & $2.76(1.71-4.45)$ & 3 \\
\hline$\leq 100$ & 63 & 48 & 1.40 & $4.07(2.28-7.26)$ & 3 \\
\hline \multicolumn{6}{|l|}{ Arterial pH } \\
\hline$\geq 7.35$ & 193 & 993 & 0 & 1 (Ref) & \\
\hline$<7.35$ & 84 & 64 & 0.82 & $2.27(1.41-3.66)$ & 2 \\
\hline \multicolumn{6}{|l|}{$\mathrm{PaCO}_{2}, \mathrm{mmHg}$} \\
\hline$\leq 45$ & 182 & 940 & 0 & 1 (Ref) & \\
\hline$>45$ & 95 & 117 & 0.91 & $2.47(1.60-3.82)$ & 2 \\
\hline \multicolumn{6}{|l|}{$\mathrm{HCO}_{3}{ }^{-}, \mathrm{mmol} / \mathrm{L}$} \\
\hline$\geq 20$ & 218 & 946 & 0 & 1 (Ref) & \\
\hline$<20$ & 59 & 111 & 0.59 & $1.80(1.14-2.83)$ & 1 \\
\hline \multicolumn{6}{|l|}{ Pleural effusion } \\
\hline No & 178 & 832 & 0 & 1 (Ref) & \\
\hline Yes & 99 & 225 & 0.52 & $1.68(1.18-2.39)$ & 1 \\
\hline \multicolumn{6}{|l|}{ Extent of total infiltration } \\
\hline$<1 / 3$ of unilateral lung & 71 & 580 & 0 & 1 (Ref) & \\
\hline $1 / 3-2 / 3$ of unilateral lung & 100 & 315 & 0.48 & $1.62(1.09-2.39)$ & 1 \\
\hline$>2 / 3$ of unilateral lung & 106 & 162 & 0.74 & $2.10(1.36-3.24)$ & 2 \\
\hline
\end{tabular}

Definition of abbreviations: $\mathrm{OR}$, odds ratio; $\mathrm{Cl}$, confidence interval; Ref, reference

* Severe adverse events included death and requirement of mechanical ventilation (invasive or noninvasive) or vasopressor support within 30 days after pneumonia diagnosis

${ }^{\dagger}$ Points were developed by rounding $\beta$-coefficients as follows: $\beta$-coefficient: $0.2-0.6,1$ point; $0.6-1.0,2$ points; and 1.0-1.4, 3 points 


\section{ALL-COP SCORE}

\begin{tabular}{|c|c|c|c|}
\hline \multirow[b]{2}{*}{ Risk factor } & \multicolumn{3}{|c|}{ Point } \\
\hline & 3 & 2 & 1 \\
\hline A Albumin, g/dL & & $<2.0$ & $2.0-3.0$ \\
\hline 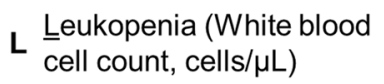 & $<4,000$ & & \\
\hline L Chronic lung disease & & & Yes \\
\hline C $\frac{\text { Confusion }}{\text { (altered mental status) }}$ & & Yes & \\
\hline $\mathrm{O} \mathrm{Pa}_{2} / \mathrm{F}_{1} \mathrm{O}_{2}$ ratio, $\mathrm{mmHg}$ & $<200$ & & $200-300$ \\
\hline Potassium, mEq/L & & $\geq 5.0$ & \\
\hline Arterial $\mathrm{pH}$ & & $<7.35$ & \\
\hline S Systolic BP, mmHg & & $<90$ & \\
\hline C $\mathrm{PaCO}_{2}, \mathrm{mmHg}$ & & $>45$ & \\
\hline $\mathrm{O} \mathrm{HCO}_{3}{ }^{-}, \mathrm{mmol} / \mathrm{L}$ & & & $<20$ \\
\hline $\mathbf{R}$ Respiratory rate, /min & & & $>30$ \\
\hline Pleural effusion & & & Yes \\
\hline $\begin{array}{l}\text { E Extent of total chest } \\
\text { radiographical infiltration } \\
\text { in unilateral lung }\end{array}$ & & $>2 / 3$ & $1 / 3-2 / 3$ \\
\hline $\begin{array}{l}\text { Fig. } 2 \text { ALL-COP SCORE rule. The AL } \\
\text { that was developed based on a mu } \\
\text { model, comprises } 13 \text { variables. Each } \\
\text { and } 3 \text { points by rounding } \beta \text {-coeffic } \\
\text { the ALL-COP SCORE is between } 0 \text { ( }\end{array}$ & $\begin{array}{l}\text {-COP SCO } \\
\text { tivariate lo } \\
\text { variable is } \\
\text { ents (Table } \\
\text { in) and } 24\end{array}$ & $\begin{array}{l}\text { E, a scorir } \\
\text { istic regre } \\
\text { assigned } k \\
\text { 2). The po } \\
\text { (max) }\end{array}$ & $\begin{array}{l}\text { g system } \\
\text { ssion } \\
\text { netween } 1 \\
\text { nt range of }\end{array}$ \\
\hline
\end{tabular}

pressure (<90 mmHg, 2 points); $\mathrm{PaCO}_{2}(>45 \mathrm{mmHg}, 2$ points); $\mathrm{HCO}_{3}{ }^{-}(<20 \mathrm{mmol} / \mathrm{L}, 1$ point); respiratory rate ( $\geq 30$ breaths $/ \mathrm{min}, 1$ point); pleural effusion (1 point); and extent of total chest radiographical infiltration of unilateral lung ( $>2 / 3,2$ points; $1 / 2-2 / 3,1$ point). The ROC curve was similar between the ALL-COP SCORE rule and the original logistic regression model, and the AUROC was the same between the two models (0.84 [95\% CI, 0.81-0.86] and 0.84 [95\% CI, 0.81-0.87] for the ALL-COP SCORE rule and the original logistic regression model, respectively) (Additional file 3A). The sensitivity, specificity, and Youden's index (sensitivity plus specificity minus one) for each point of the ALLCOP SCORE rule in the derivation cohort are shown in Additional file 3B. Since an ALL-COP SCORE threshold of $\geq 4$ points had a specificity of $\geq 60 \%$ (Fig. 3, Additional file $3 \mathrm{~B}$ ) and as higher sensitivity was preferable to determine inpatients who should receive higher-intensity treatment, as described in the Methods, we determined $\geq 4$ points as the ALL-COP SCORE threshold for identifying patients with CAP at high risk for SAEs at the time of pneumonia diagnosis.

\section{Prediction model performance for SAEs in the validation cohort}

Figure 3A shows the probabilities of SAEs within 30 days after pneumonia diagnosis according to the ALL-COP SCORE rule in the validation cohort. Patients with $4-5,6-7$, and $\geq 8$ points had $17 \%, 35 \%$, and $52 \%$ increase in the probability of SAEs, respectively, whereas the probability of SAEs was $3 \%$ in patients with $\leq 3$ points. An ALL-COP SCORE threshold of $\geq 4$ points had a sensitivity of $91.7 \%$ and a specificity of $60.0 \%$, with a PPV of $34.5 \%$, a NPV of $96.9 \%$, a PLR of 2.3, and a NLR of 0.1. The ALL-COP SCORE
A

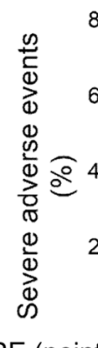

ALL-COP SCORE (points)
B

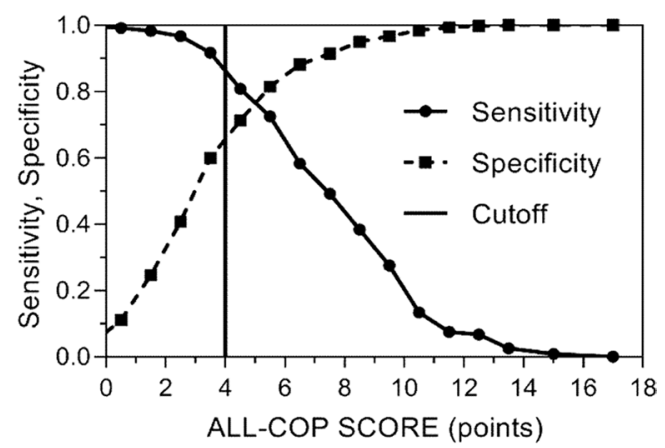

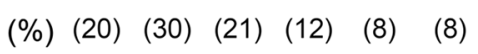

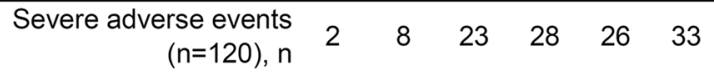

$\begin{array}{llllll}\% & (2) \quad(4) \quad(17) \quad(35) \quad(48) \quad(66)\end{array}$

Fig. 3 A Prevalence of patients with severe adverse events according to ALL-COP SCORE points in the validation cohort. B Sensitivity and specificity of the ALL-COP SCORE rule in the validation cohort. An ALL-COP SCORE $\geq 4$ points has a sensitivity of $92 \%$ and a specificity of $60 \%$ 


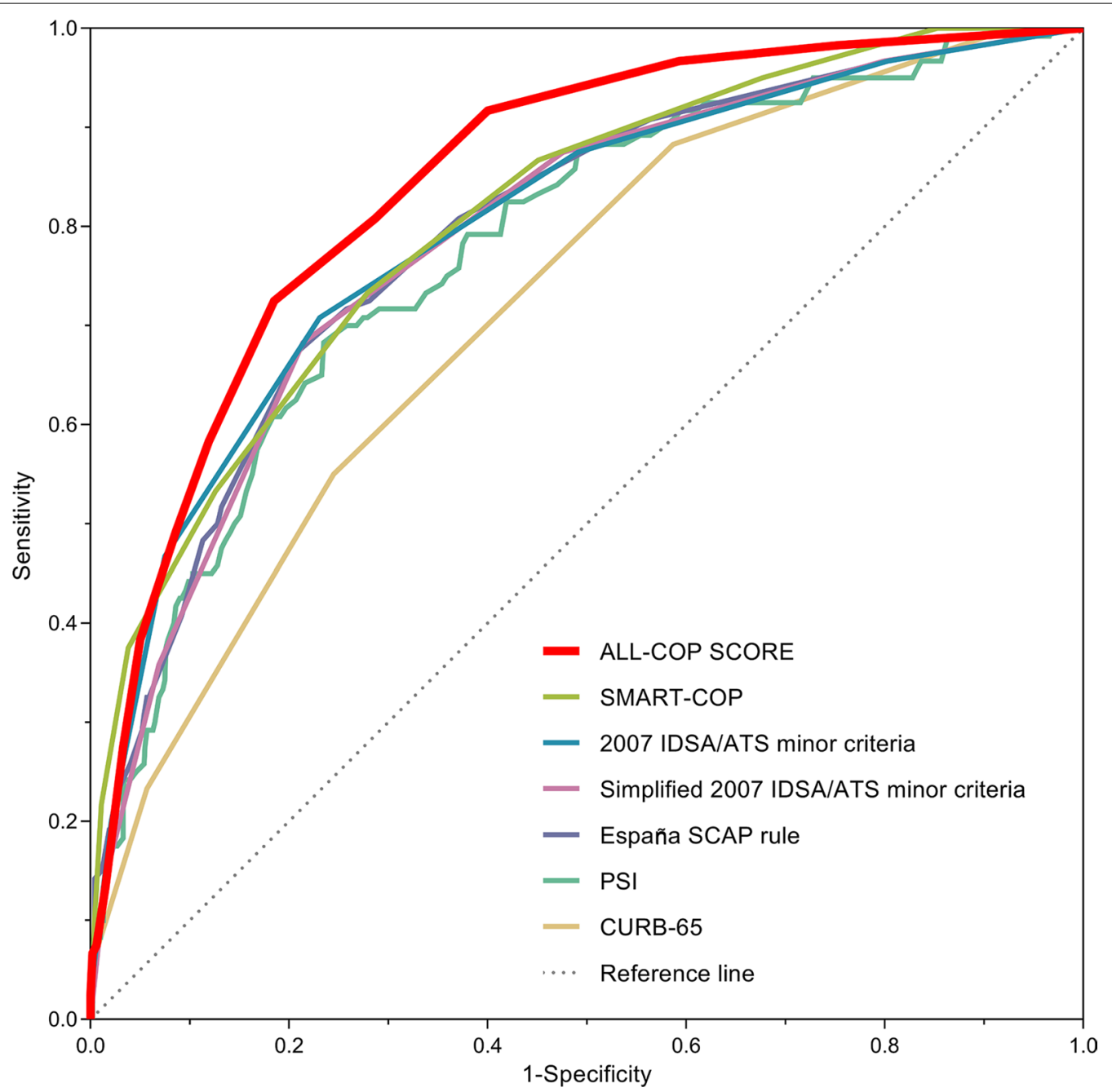

Fig. 4 Comparison of the receiver operating characteristic curves of the prediction rules for severe adverse events in the validation cohort. Definition of abbreviations: SMART-COP, systolic blood pressure, multilobar chest $X$-ray involvement, albumin, respiratory rate, tachycardia, confusion, oxygenation, and arterial pH; IDSA/ATS, Infectious Disease Society of America/American Thoracic Society; SCAP, severe community-acquired pneumonia; PSI, Pneumonia Severity Index; CURB-65, confusion, urea level, respiratory rate, blood pressure, and age $\geq 65$ years

rule exhibited a higher AUROC (0.85) compared with the other predictive models (Fig. 4, Table 3). The sensitivity of the ALL-COP SCORE rule was higher than those of the España SCAP rule, SMART-COP, 2007 IDSA/ATS minor criteria, and simplified 2007 IDSA/ ATS minor criteria. Comparison of the sensitivities of the tested predictive models at the same level of specificity $(0.60$, the specificity of $\geq 4$ points by the ALL-COP SCORE rule) and the same comparisons conducted after changing the thresholds so that the specificities were close to between 60 and $70 \%$ among the tested models revealed that the sensitivity of the ALL-COP SCORE rule was the highest among the evaluated predictive models (Fig. 4, Table 3).

\section{Subgroup analyses}

Table 4 shows the results of the predictive performance of the ALL-COP SCORE rule in patient subgroups. The predictivity of the ALL-COP SCORE rule was more accurate when the rule was applied to patients without potential treatment restrictions. Specifically, compared to all patients in the validation cohort, the sensitivity was the same $(91.2 \%)$, whereas the specificity increased by $10 \%(70.5 \%)$ (Table 3$)$ in the subgroup of patients without potential treatment restrictions, which included $280(81.9 \%)$ patients with CAP excluding HCAP and 62 (18.1\%) patients with HCAP. The assessment of patients without invasive MV/VS at admission and those without immunosuppression revealed that the predictive 
Table 3 Comparison of the prediction rules for adverse outcomes in the validation cohort

\begin{tabular}{|c|c|c|c|c|c|c|c|c|}
\hline Rule & Cutoff & $\begin{array}{l}\text { Sensitivity, \% } \\
(95 \% \mathrm{Cl})\end{array}$ & $\begin{array}{l}\text { Specificity, \% } \\
(95 \% \mathrm{Cl})\end{array}$ & $\begin{array}{l}\text { PPV, \% (95\% } \\
\text { CI) }\end{array}$ & $\begin{array}{l}\text { NPV, \% (95\% } \\
\text { Cl) }\end{array}$ & PLR $(95 \% \mathrm{Cl})$ & NLR $(95 \% \mathrm{Cl})$ & $\begin{array}{l}\text { AUROC }(95 \% \\
\text { Cl) }\end{array}$ \\
\hline \multirow[t]{3}{*}{ ALL-COP SCORE } & $\geq 4$ Points & $91.7(85.3-95.4)$ & 60.0 & $34.5(29.5-39.9)$ & $96.9(94.4-98.3)$ & $2.3(2.0-2.6)$ & $0.1(0.1-0.3)$ & $0.85(0.81-0.88)$ \\
\hline & $\geq 5$ Points & 80.8 (72.9-86.9) & $71.3(67.3-75.0)$ & $39.3(33.4-45.5)$ & $94.2(91.4-96.1)$ & $2.8(2.4-3.3)$ & $0.3(0.2-0.4)$ & \\
\hline & $\geq 6$ Points & $72.5(63.9-79.7)$ & $81.5(77.9-84.6)$ & $47.3(40.2-54.5)$ & $92.8(90.1-94.8)$ & $3.9(3.2-4.8)$ & $0.3(0.3-0.5)$ & \\
\hline \multirow[t]{2}{*}{ SMART-COP } & $\begin{array}{l}\geq 3 \text { Points } \\
\text { (original) }\end{array}$ & 86.7 (79.4-91.6) & $54.9(50.6-59.1)$ & $30.6(25.9-35.7)$ & $94.7(91.6-96.7)$ & $1.9(1.7-2.2)$ & $0.2(0.2-0.4)$ & $0.81(0.77-0.85)$ \\
\hline & $\geq 4$ Points & $73.3(64.8-80.4)$ & $72.1(68.1-75.8)$ & $37.6(31.7-44.0)$ & $92.2(89.2-94.4)$ & $2.6(2.2-3.1)$ & $0.4(0.3-0.5)$ & \\
\hline \multirow[t]{2}{*}{$\begin{array}{l}2007 \text { IDSA/ATS } \\
\text { criteria }\end{array}$} & $\begin{array}{l}\text { Major criteria } \\
\text { and/or } \geq 3 \\
\text { minor criteria } \\
\text { (original) }\end{array}$ & $72.5(63.9-79.7)$ & $76.9(73.1-80.3)$ & $41.8(35.3-48.6)$ & $92.4(89.5-94.6)$ & $3.1(2.6-3.8)$ & $0.4(0.3-0.5)$ & - \\
\hline & $\begin{array}{l}\text { Major criteria } \\
\text { and/or } \geq 2 \\
\text { minor criteria }\end{array}$ & $87.5(80.4-92.3)$ & $50.9(46.6-55.1)$ & $29.0(24.6-33.9)$ & 94.7 (91.4-96.7) & $1.8(1.6-2.0)$ & $0.2(0.2-0.4)$ & \\
\hline \multirow[t]{2}{*}{$\begin{array}{l}2007 \text { IDSA/ATS } \\
\text { minor criteria }\end{array}$} & $\begin{array}{l}\geq 3 \text { Minor cri- } \\
\text { teria (original) }\end{array}$ & $70.8(62.2-78.2)$ & $76.9(73.1-80.3)$ & $41.3(34.8-48.1)$ & $92.0(89.1-94.2)$ & $3.1(2.5-3.7)$ & $0.4(0.3-0.5)$ & $0.80(0.75-0.85)$ \\
\hline & $\begin{array}{l}\geq 2 \text { Minor } \\
\text { criteria }\end{array}$ & $87.5(80.4-92.3)$ & 50.9 & $29.0(24.6-33.9)$ & $94.7(91.4-96.7)$ & $1.8(1.6-2.0)$ & $0.2(0.2-0.4)$ & \\
\hline \multirow{2}{*}{$\begin{array}{l}\text { Simplified } 2007 \\
\text { IDSA/ATS minor } \\
\text { criteria }\end{array}$} & $\begin{array}{l}\geq 3 \text { Minor cri- } \\
\text { teria (original) }\end{array}$ & $68.3(59.6-76.0)$ & 78.6 (74.9-81.9) & $42.3(35.5-49.3)$ & 91.5 (88.6-93.8) & $3.2(2.6-3.9)$ & $0.4(0.3-0.5)$ & $0.79(0.74-0.83)$ \\
\hline & $\begin{array}{l}\geq 2 \text { Minor } \\
\text { criteria }\end{array}$ & $87.5(80.4-92.3)$ & $52.4(48.1-56.6)$ & $29.7(25.1-34.6)$ & $94.8(91.6-96.8)$ & $1.8(1.6-2.1)$ & $0.2(0.1-0.4)$ & \\
\hline \multirow[t]{2}{*}{$\begin{array}{l}\text { España SCAP } \\
\text { rule }\end{array}$} & $\begin{array}{l}\geq 10 \text { Points } \\
\text { (original) }\end{array}$ & $88.3(81.4-92.9)$ & 49.0 & $28.4(24.1-33.2)$ & $94.8(91.5-96.9)$ & $1.7(1.6-1.9)$ & $0.2(0.1-0.4)$ & $0.79(0.75-0.84)$ \\
\hline & $\geq 11$ Points & 80.8 (72.9-86.9) & $62.9(58.7-66.9)$ & $33.3(28.2-38.9)$ & 93.5 (90.4-95.6) & $2.2(1.9-2.5)$ & $0.3(0.2-0.4)$ & \\
\hline \multirow[t]{2}{*}{ PSI } & $\begin{array}{l}\text { Classes IV and V } \\
\text { (original) }\end{array}$ & $92.5(86.4-96.0)$ & $35.6(31.6-39.8)$ & $24.8(21.0-29.0)$ & $95.4(91.5-97.6)$ & $1.4(1.3-1.6)$ & $0.2(0.1-0.4)$ & $0.78(0.73-0.82)$ \\
\hline & Class V & $61.7(52.7-69.9)$ & $80.3(76.7-83.5)$ & $41.8(34.8-49.2)$ & $90.1(87.1-92.5)$ & $3.1(2.5-3.9)$ & $0.5(0.4-0.6)$ & \\
\hline \multirow[t]{2}{*}{ CURB-65 } & $\begin{array}{l}\geq 3 \text { Points } \\
\text { (original) }\end{array}$ & $55.0(46.1-63.6)$ & $75.5(71.7-79.0)$ & $34.0(27.7-40.9)$ & $88.0(84.6-90.7)$ & $2.2(1.8-2.8)$ & $0.6(0.5-0.7)$ & $0.72(0.67-0.77)$ \\
\hline & $\geq 2$ Points & $88.3(81.4-92.9)$ & $41.3(37.2-45.6)$ & $25.7(21.7-30.1)$ & $93.9(90.0-96.3)$ & $1.5(1.4-1.7)$ & $0.3(0.2-0.5)$ & \\
\hline
\end{tabular}

Definition of abbreviations: $\mathrm{Cl}$, confidence interval; PPV, positive predictive value; NPV, negative predictive value; PLR, positive likelihood ratio; NLR, negative likelihood ratio; AUROC, area under the receiver operating characteristic curve; SMART-COP, systolic blood pressure, multilobar chest X-ray involvement, albumin, respiratory rate, tachycardia, confusion, oxygenation, and arterial PH; IDSA/ATS, Infectious Disease Society of America/American Thoracic Society; SCAP, severe community-acquired pneumonia; PSI, Pneumonia Severity Index; CURB-65, confusion, urea level, respiratory rate, blood pressure, and age $\geq 65$ years

performance of the ALL-COP SCORE rule was almost identical between each subgroup and the entire validation cohort.

The assessment for the performance of the ALL-COP SCORE rule in secondary endpoints in the validation cohort revealed that an ALL-COP SCORE threshold of $\geq 4$ points had a sensitivity of $90.0 \%$ and a specificity of $54.6 \%$ for 30 -day mortality, a sensitivity of $93.2 \%$ and a specificity of $56.1 \%$ for the requirement of MV/VS, and a sensitivity of $90.9 \%$ and a specificity of $55.1 \%$ for ICU admission (Additional file 4).

\section{Discussion}

In the present study, we developed and validated the ALL-COP SCORE prediction rule for its utility in all patients with CAP including those with HCAP. The ALL-COP SCORE rule exhibited a high AUROC (0.85), and an ALL-COP SCORE threshold of $\geq 4$ points showed a high sensitivity (92\%) with $60 \%$ specificity for predicting SAEs. These results indicated that the proposed ALL-COP SCORE prediction rule may be useful for identifying patients at high risk for SAEs at the time of CAP diagnosis.

The optimal definition of severe CAP, which remains a topic of debate $[5-9,23]$, should be used as a guide during decision-making on identifying patients who require a higher level of inpatient treatment intensity. The 30-day mortality was adopted as a primary outcome measure to identify patients with mild CAP who could be treated as outpatients, as described in the original studies on the PSI and CURB-65 [1-3, 24, 25]. Conversely, several previous studies adopted ICU admission as the primary outcome measure to identify patients who should receive higher-intensity treatment for severe pneumonia [26-29]. However, some concerns remain that using ICU admission as an outcome measure might prevent 
Table 4 Performance of the ALL-COP SCORE for predicting severe adverse events in validation cohort subgroups

\begin{tabular}{|c|c|c|c|c|c|c|c|c|c|}
\hline Subgroups & $\mathrm{n}$ & $\begin{array}{l}\text { Severe } \\
\text { adverse } \\
\text { events*, } n \\
(\%)\end{array}$ & $\begin{array}{l}\text { Sensitivity, \% } \\
(95 \% \text { CI) }\end{array}$ & $\begin{array}{l}\text { Specificity, \% } \\
(95 \% \text { Cl) }\end{array}$ & $\begin{array}{l}\text { PPV, \% (95\% } \\
\text { Cl) }\end{array}$ & $\begin{array}{l}\text { NPV, \% (95\% } \\
\text { Cl) }\end{array}$ & PLR (95\% CI) & NLR $(95 \% \mathrm{Cl})$ & $\begin{array}{l}\text { AUROC (95\% } \\
\text { Cl) }\end{array}$ \\
\hline $\begin{array}{l}\text { Patients with- } \\
\text { out potential } \\
\text { treatment } \\
\text { restriction }\end{array}$ & 342 & $57(16.7)$ & $91.2(81.1-96.2)$ & ) 70.5 (65.0-75.5) & $38.2(30.5-46.6)$ & $97.6(94.4-99.0)$ & $3.1(2.5-3.8)$ & $0.1(0.1-0.3)$ & $0.89(0.84-0.94)$ \\
\hline $\begin{array}{l}\text { CAP excluding } \\
\text { HCAP }^{\ddagger}\end{array}$ & 437 & $71(16.2)$ & $94.4(86.4-97.8)$ & ) $65.0(60.0-69.7)$ & $34.3(28.1-41.3)$ & $98.4(95.8-99.4)$ & $2.7(2.3-3.1)$ & $0.1(0.0-0.2)$ & $0.88(0.84-0.92)$ \\
\hline HCAP§ & 206 & $49(23.8)$ & $87.8(75.8-94.3)$ & $48.4(40.7-56.2)$ & $34.7(26.9-43.4)$ & $92.7(84.9-96.6)$ & $1.7(1.4-2.0)$ & $0.3(0.1-0.5)$ & $0.78(0.70-0.85)$ \\
\hline $\begin{array}{l}\text { Patients } \\
\text { without } \\
\text { requirement } \\
\text { of invasive } \\
\text { MVNS at } \\
\text { admission }\end{array}$ & 629 & $106(16.9)$ & 91.5 (84.7-95.5) & ) $60.0(55.8-64.2)$ & $31.7(26.7-37.1)$ & $97.2(95.0-98.5)$ & $2.3(2.0-2.6)$ & $0.1(0.1-0.3)$ & $0.84(0.80-0.88)$ \\
\hline $\begin{array}{l}\text { Patients } \\
\text { without } \\
\text { immunosup- } \\
\text { pression** }\end{array}$ & 585 & 105 (17.9) & $91.4(84.5-95.4)$ & ) $60.0(56.0-64.7)$ & $33.6(28.3-39.2)$ & $97.0(94.4-98.4)$ & $2.3(2.0-2.6)$ & $0.1(0.1-0.3)$ & $0.84(0.80-0.88)$ \\
\hline
\end{tabular}

Definition of abbreviations: $\mathrm{Cl}$, confidence interval; PPV, positive predictive value; NPV, negative predictive value; PLR, positive likelihood ratio; NLR, negative likelihood ratio; AUROC, area under the receiver operating characteristic curve; CAP, community-acquired pneumonia; $\mathrm{HCAP}$, healthcare-associated pneumonia; $M V$, mechanical ventilation; VS, vasopressor support

* Severe adverse events included death and requirement of mechanical ventilation (invasive or noninvasive) or vasopressor support within 30 days after pneumonia diagnosis

${ }^{\dagger}$ Patients without potential treatment restriction were defined as those under 80 years and without nonambulatory status (who were able to walk)

${ }^{\ddagger}$ CAP excluding HCAP was defined as pneumonia that did not match the criteria for hospital-acquired pneumonia (pneumonia occurring $48 \mathrm{~h}$ or more after hospital admission)

${ }^{\S} \mathrm{HCAP}$ was defined as pneumonia co-occurring with any of the following conditions: hospitalization for 2 days or more during the preceding 90 days, residence in a nursing home or extended care facility, home intravenous therapy (including antibiotics and chemotherapy), chronic dialysis (including hemodialysis and peritoneal dialysis) during the preceding 30 days, or home wound care during the preceding 30 days

"l Patients who required invasive MV/VS at admission were excluded

${ }^{* *}$ Immunosuppression included any immunosuppressive diseases, such as congenital or acquired immunodeficiency, hematologic diseases, asplenia and neutropenia $(<1000$ cells $/ \mu \mathrm{L})$, treatment with immunosuppressive agents, chemotherapy within the previous 30 days, or corticosteroids in daily doses of at least $10 \mathrm{mg} /$ day of a prednisone equivalent for more than 2 weeks

the generalizability of findings due to regional differences in the ICU admission criteria depending on medical resources $[5,6,9,21]$. Thus, España and colleagues adopted a composite endpoint including MV, septic shock, and death to develop the España SCAP rule [5], whereas Charles and colleagues employed intensive respiratory or VS as a primary outcome measure to develop the SMART-COP [6]. Regarding this outcome measure, some researchers adovocate death should not be combined with MV or VS. However, Torsten and colleagues showed that, even patients residing in nursing homes and bedridden patients were excluded, $76.3 \%$ of nonsurvivors of CAP did not receive ventilatory support $(62.6 \%$ of those aged $<65$ years) [30]. They stated that the number of nonsurvivors without obvious reasons for withholding ventilatory support was high, particularly in younger patients, and suggested that these high percentages might reflect either treatment restrictions or deficient clinical performance. Therefore, considering future contribution to improve the clinical performance, we defined SAEs as a primary outcome measure and included death and requirement of MV or VS within 30 days after pneumonia diagnosis.

We considered that a model with high sensitivity would be preferable when identifying patients at high risk for SAEs and those who should receive higher-intensity treatment. The 2019 ATS/IDSA CAP guidelines suggest that the 2007 IDSA/ATS severity criteria should be used. However, the AUROC of the ALL-COP SCORE rule was highest among the tested predictive models including the 2007 IDSA/ATS criteria. The sensitivity of the ALLCOP SCORE rule was high at $92 \%$, with a specificity of $60 \%$, when the threshold to identify patients with SAEs was set at $\geq 4$ points. The sensitivity of the ALL-COP SCORE rule was the highest when compared to the other tested predictive rules at the same specificity level of $60 \%$. Several reasons might potentially explain the high predictive ability of the ALL-COP SCORE rule. First, the ALL-COP SCORE rule includes several variables such as hypercapnia and hyperkalemia, which are not included 
in the other tested prediction models, although they are reported as prognostic factors for pneumonia [16, 17]. Second, we adopted ternary or quaternary variables, as well as binary variables, because ternary or quaternary variables provided more accurate effects for SAEs compared with the binary variables that were used in the existing prediction rules $[1-3,5,6]$. Findings of the present study also suggest that the examination of some variables, such as serum albumin, $\mathrm{PaO}_{2}$, and $\mathrm{pH}$, which might not be universally available for real-time clinical decision-making [4], might still be worthwhile to assess at the time of pneumonia diagnosis to improve patient care.

The predictive performance of the ALL-COP SCORE rule was improved when patients with possible treatment restrictions were excluded, suggesting that this prediction model may be more useful as a decision-making tool to identify patients requiring intensive care among those without treatment restrictions. Specifically, in the absence of treatment restrictions, physicians should aggressively consider higher-intensity treatment at the time of pneumonia diagnosis in patients with $\geq 4$ points according to the ALL-COP SCORE rule. Furthermore, these patients might be strongly recommended for early interventions such as CAP bundle of care [31] (e.g., rapid empirical antibiotic administration with a $\beta$-lactam and macrolide [32-34], rapid resuscitation, thromboembolic prophylaxis, and appropriate management for hypoxia [35-38]).

The present study has several limitations. First, the biggest one is that data in two cohorts used in this study was obtained before the coronavirus disease 2019 (COVID19) pandemic. We are going to validate whether the ALLCOP SCORE rule can be useful in both patient groups of COVID-19 and non-COVID-19 pneumonia. One important future research question is whether prediction models for worse outcomes can be adopted in all CAP including COVID-19 or should be separately considered in COVID-19 and non-COVID-19. Second, there were 13 constitutive variables as part of the ALL-COP SCORE rule, more than those of the other predictive rules $[1,3,5$, $6,20]$. This limitation can be overcome if the ALL-COP SCORE rule is used as a calculation tool in a medical application software or can be combined with an electric medical record system. Third, the present study did not confirm do-not-resuscitate orders at the time of admission. Elderly patients or those with poor functional status might have had various potential treatment restrictions even in the absence of a do-not-resuscitate order. Thus, we defined patients aged 80 years or older and any patient without independent ambulation as those with potential treatment restrictions. Fourth, the present study was performed in Japan which might hinder the international generalizability of the ALL-COP SCORE rule. Therefore, international collaborative studies for further validation of this model are necessary in the future. Furthermore, the efficacy and safety of the ALL-COP SCORE rule as a decision aid to guide treatment intensity should be assessed.

\section{Conclusions}

The ALL-COP SCORE is a potentially useful tool to predict patients at high risk for SAEs within 30 days after pneumonia diagnosis and can be adopted to all patients with CAP including those with HCAP. Higher-intensity treatment should be considered in patients with CAP and an ALL-COP SCORE threshold of $\geq 4$ points.

\begin{abstract}
Abbreviations
CAP: Community-acquired pneumonia; PSI: Pneumonia Severity Index; CURB-65: Confusion, blood urea nitrogen $>7 \mathrm{mmol} / \mathrm{L}[20 \mathrm{mg} / \mathrm{dL}]$, respiratory

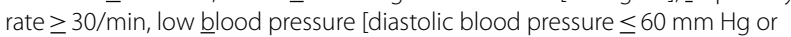
systolic blood pressure $<90 \mathrm{~mm} \mathrm{Hg}$, and age $\geq \underline{65}$ years; SAE: Severe adverse event; IDSA: Infectious Diseases Society of America; ATS: American Thoracic Society; HCAP: Healthcare-associated pneumonia; MV: Mechanical ventilation; VS: Vasopressor support; ICU: Intensive care unit; OR: Odds ratio; Cl: Confidence interval; ROC: Receiver operating characteristic; PPV: Positive predictive value; NPV: Negative predictive value; AUROC: Area under the receiver operating characteristic curve; COVID-19: Coronavirus disease 2019.
\end{abstract}

\section{Supplementary Information}

The online version contains supplementary material available at https://doi. org/10.1186/s12890-022-01819-0.

Additional file 1. Methodological Details. Details on pneumonia definitions and categories, inclusion and exclusion criteria, definitions of variables, procedures, and data collection.

Additional file 2. Supplemental Table 1. Univariate analysis for severe adverse events in the derivation cohort.

Additional file 3. Supplemental Figure A, B. Receiver operating characteristic curves of the multivariate logistic regression model and the ALL-COP SCORE rule in the derivation cohort (A). Sensitivity, specificity, and Youden's index at each point of the ALL-COP SCORE rule in the derivation cohort (B)

Additional file 4. Supplemental Table 2. Comparison of rules predicting for secondary endpoints in the validation cohort.

\section{Acknowledgements}

We thank Drs. Ryota Ito, Akira Shiraki, Yasuhiro Goto, Yasutaka Fukui, Mai Iwaki, Yuka Tomita, Mitsutaka Iguchi, Motoshi Ichikawa, Tomohiko Ogasawara, Yoshimasa Tanikawa, Yasuteru Sugino, Joe Shindoh, Fumio Nomura, Masashi Yamamoto, Hiroyuki Taniguchi, Hiroshi Saito, Ryujiro Suzuki for the acquisition of data; Drs. Mitsuaki Yagi, Hironori Kobayashi, and Nancy Thabet for their comments on the manuscript; and Drs. Shigeru Yoshida and Masaki Takahashi for their advice to set up the electronic data collection system. We are indebted to all members of the Central Japan Lung Study Group who supported this study, the clinical research coordinators (Kyoko Kazeto, Sumiyo Tanaka, Mika Yamauchi, Mayumi Tsuda, Junko Hisada, Yuko Okada, Tomoe Kushihara, Hideaki Sobajima, Harumi Nakano, Mieko Sakuma, and Asuka Miyake), laboratory staff (Ikuo Yamaguchi, Mariko Mochizuki, Miho Saito, Yoshiko Sugaki, Yuko Asano, Tomomi Torii, Yasue Hayakawa, Yusuke Nishida, Takae Aoki, Yuki Nagata, Hideki Nishiyama, Sachie Asai, Nobuya Sakagami, and Jun Sokunaga), and all healthcare professionals who participated in the data collection. 


\section{Authors' contributions}

Study concept and design: T.S., Y.S., M.S. J.O., Y.M., K.T., and S.M.; Acquisition of data:Y.S., D.K., T.S., M.S., J.O., T.Y., and H.S.; Cleaning up the data:Y.S., D.K., T.S., M.S., and J.O.; Writing the statistical analysis plan: T.S., Y.S., K.T., and S.M.; Analysis and interpretation of data:T.S., Y.S., M.S., J.O., Y.M., K.T., and S.M.; Drafting of the manuscript:T.S., Y. S., M.S., J.O., Y.M., K.T., and S.M.; Critical revision of the manuscript for important intellectual content:T.S., Y.S., M.S., J.O., Y.M., K.T., and S.M.; Statistical analysis: T.S., Y.S., K.T., and S.M.; Study supervision: H.S. and Y.H.; Final approval: all authors. All authors read and approved the final manuscript.

\section{Funding}

This work was partially supported by Japan Society for the Promotion of Science KAKENHI (grant number 20K08517). This study was also supported by the Central Japan Lung Study Group (CJLSG), a nonprofit organization supported by unrestricted donations from the following pharmaceutical companies: Chugai Pharmaceutical Co., Ltd.; Shionogi \& Co., Ltd.; Daiichi Sankyo Co., Ltd.; Dainippon Sumitomo Pharma Co., Ltd.; Janssen Pharmaceutical K.K.; Eli Lilly Japan K.K.; Taisho Toyama Pharmaceutical Co., Ltd.; Meiji Seika Pharma Co., Ltd.; MSD K.K.; Bayer Holding Ltd.; Astellas Pharma Inc.; and Nippon Boehringer Ingelheim Co., Ltd.

\section{Availability of data and materials}

Original data and analyses are available from the corresponding author on reasonable request.

\section{Declarations}

\section{Ethics approval and consent to participate}

The study protocol adhered to the Declaration of Helsinki and the Japanese Ethics Guidelines for Epidemiological Studies. The study was approved by the ethics committee of Nagoya University and respective institutional review boards of the participating institutions. Informed consent of the participants was waived, but the opt-out method was adopted according to the ethics guidelines.

\section{Consent for publication}

Not applicable.

\section{Competing interests}

All of the following information provide relevant financial activities outside the submitted work. Dr. Shindo reports personal fees (payment for lectures including service on speakers bureaus) from Pfizer Inc., Shionogi \& Co., Ltd., MSD K.K., Taisho Toyama Pharmaceutical Co., Ltd., Toyama Chemical Co., Ltd., Sawai Pharmaceutical Co., Ltd., Meiji Seika Pharma Co., Ltd., Kyowa Hakko Kirin Co., Ltd., Astellas Pharma Inc., AstraZeneca K.K., KYORIN Pharmaceutical Co.,Ltd., DAIICHI SANKYO COMPANY, LIMITED, and Nippon Boehringer Ingelheim Co. Ltd. Dr. Yagi reports grants and personal fees (payment for lectures including service on speakers bureaus) from Taisho Toyama Pharmaceutical Co., Ltd., Shionogi \& Co., Ltd., Pfizer Inc., Daiichi Sankyo Co., Ltd., Meiji Seika Pharma Co., Ltd., MSD K.K., Dainippon Sumitomo Pharma Co., Ltd., Taisho Toyama Pharmaceutical Co., Ltd., Shionogi \& Co., Ltd., Pfizer Inc., Asahi Kasei Pharma Co., Ltd., Daiichi Sankyo Co., Ltd., Meiji Seika Pharma Co., Ltd., Astellas Pharma Inc., Dainippon Sumitomo Pharma Co., Ltd., Mitsubishi Tanabe Pharma., MSD K.K, Beckton Dickinson and Company, Saraya Co., Ltd., KYORIN Pharmaceutical Co.,Ltd., Beckman Coulter, Inc., TERUMO CORPORATION, Oxford Immunotec Ltd., MIYARISAN PHARMACEUTICAL CO., Kao Professional Services, and Kyowa Hakko Kirin Co., Ltd. Dr. Saka reports grants from Taisho Toyama Pharmaceutical Co., Ltd., Shionogi \& Co., Ltd., Pfizer Inc., Chugai Pharmaceutical Co., Ltd., Dainippon Sumitomo Pharma Co., Ltd., Bristol-Myers Squibb Company, Kyowa Hakko Kirin Co., Ltd., Eisai Co., Ltd., Ono Pharmaceutical Co., Ltd., Boehringer Ingelheim Co., Ltd., MSD K.K., Eli Lilly Japan K. K., Daiichi Sankyo CO., LTD., Astrazeneca K. K., Novartis Phama K. K., Taiho Pharmaceutical Co., LTD., Sanofi K. K., and Bayer Yakuhin, Ltd. Dr. Hasegawa reports grants and personal fees (payment for lectures including service on speakers bureaus) from Chugai Pharmaceutical Co., Ltd., Shionogi \& Co., Ltd., Taiho Pharmaceutical Co., Ltd., MSD K.K., and Pfizer Japan Inc.

\section{Author details}

1 Department of Respiratory Medicine, Nagoya University Graduate School of Medicine, 65 Tsurumai-cho, Showa-ku, Nagoya 466-8550, Japan. ${ }^{2}$ Kyoto
University Health Service, Kyoto, Japan. ${ }^{3}$ Department of Respiratory Medicine, Higashi Nagoya National Hospital, Nagoya, Japan. ${ }^{4}$ Department of Respiratory Medicine, Toyota Memorial Hospital, Toyota, Japan. ${ }^{5}$ Department of Biostatistics, Nagoya University Graduate School of Medicine, Nagoya, Japan. ${ }^{6}$ Department of Biostatistics, M\&D Data Science Center, Tokyo Medical and Dental University, Tokyo, Japan. ${ }^{7}$ Department of Infectious Diseases, Nagoya University Hospital, Nagoya, Japan. ${ }^{8}$ Department of Respiratory Medicine, Matsunami General Hospital, Gifu, Japan. ${ }^{9}$ National Hospital Organization, Nagoya Medical Center, Nagoya, Japan.

Received: 19 October 2021 Accepted: 29 December 2021

Published online: 12 January 2022

\section{References}

1. Mandell LA, Wunderink RG, Anzueto A, Bartlett JG, Campbell GD, Dean NC, Dowell SF, File TM, Musher DM, Niederman MS, et al. Infectious Diseases Society of America/American Thoracic Society consensus guidelines on the management of community-acquired pneumonia in adults. Clin Infect Dis. 2007;44:S27-72.

2. Fine MJ, Auble TE, Yealy DM, Hanusa BH, Weissfeld LA, Singer DE, Coley CM, Marrie TJ, Kapoor WN. A prediction rule to identify low-risk patients with community-acquired pneumonia. N Engl J Med. 1997;336(4):243-50

3. Lim WS, van der Eerden MM, Laing R, Boersma WG, Karalus N, Town Gl, Lewis SA, Macfarlane JT. Defining community acquired pneumonia severity on presentation to hospital: an international derivation and validation study. Thorax. 2003;58(5):377-82.

4. Metlay JP, Waterer GW, Long AC, Anzueto A, Brozek J, Crothers K, Cooley $L A$, Dean NC, Fine MJ, Flanders SA, et al. Diagnosis and treatment of adults with community-acquired pneumonia. An official clinical practice guideline of the American Thoracic Society and Infectious Diseases Society of America. Am J Respir Crit Care Med. 2019;200(7):e45-67.

5. Espana PP, Capelastegui A, Gorordo I, Esteban C, Oribe M, Ortega M, Bilbao A, Quintana JM. Development and validation of a clinical prediction rule for severe community-acquired pneumonia. Am J Respir Crit Care Med. 2006;174(11):1249-56.

6. Charles PG, Wolfe R, Whitby M, Fine MJ, Fuller AJ, Stirling R, Wright AA, Ramirez JA, Christiansen KJ, Waterer GW, et al. SMART-COP: a tool for predicting the need for intensive respiratory or vasopressor support in community-acquired pneumonia. Clin Infect Dis. 2008;47(3):375-84.

7. Chalmers JD, Mandal P, Singanayagam A, Akram AR, Choudhury G, Short PM, Hill AT. Severity assessment tools to guide ICU admission in community-acquired pneumonia: systematic review and meta-analysis. Intensive Care Med. 2011;37(9):1409-20.

8. Marti C, Garin N, Grosgurin O, Poncet A, Combescure C, Carballo S, Perrier A. Prediction of severe community-acquired pneumonia: a systematic review and meta-analysis. Crit Care. 2012;16(4):R141.

9. Ewig S, Woodhead M, Torres A. Towards a sensible comprehension of severe community-acquired pneumonia. Intensive Care Med. 2011:37(2):214-23.

10. Kalil AC, Metersky ML, Klompas M, Muscedere J, Sweeney DA, Palmer LB, Napolitano LM, O'Grady NP, Bartlett JG, Carratala J, et al. Management of adults with hospital-acquired and ventilator-associated pneumonia: 2016 clinical practice guidelines by the Infectious Diseases Society of America and the American Thoracic Society. Clin Infect Dis. 2016;63(5):e61-111.

11. Shindo Y, Ito R, Kobayashi D, Ando M, Ichikawa M, Shiraki A, Goto Y, Fukui Y, Iwaki M, Okumura J, et al. Risk factors for drug-resistant pathogens in community-acquired and healthcare-associated pneumonia. Am J Respir Crit Care Med. 2013;188(8):985-95.

12. Kobayashi D, Shindo Y, Ito R, Iwaki M, Okumura J, Sakakibara T, Yamaguchi I, Yagi T, Ogasawara T, Sugino Y, et al. Validation of the prediction rules identifying drug-resistant pathogens in community-onset pneumonia. Infect Drug Resist. 2018;11:1703-13.

13. Shindo Y, Ito R, Kobayashi D, Ando M, Ichikawa M, Goto Y, Fukui Y, I waki M, Okumura J, Yamaguchi l, et al. Risk factors for 30-day mortality in patients with pneumonia who receive appropriate initial antibiotics: an observational cohort study. Lancet Infect Dis. 2015;15(9):1055-65.

14. Okumura J, Shindo Y, Takahashi K, Sano M, Sugino Y, Yagi T, Taniguchi H, Saka H, Matsui S, Hasegawa Y, et al. Mortality in patients with community-onset pneumonia at low risk of drug-resistant pathogens: 
Impact of beta-lactam plus macrolide combination therapy. Respirology. 2018;23(5):526-34.

15. American Thoracic Society. Infectious Diseases Society of America: guidelines for the management of adults with hospital-acquired, ventilatorassociated, and healthcare-associated pneumonia. Am J Respir Crit Care Med. 2005;171(4):388-416.

16. Marrie TJ, Wu L. Factors influencing in-hospital mortality in communityacquired pneumonia: a prospective study of patients not initially admitted to the ICU. Chest. 2005;127(4):1260-70

17. Laserna E, Sibila O, Aguilar PR, Mortensen EM, Anzueto A, Blanquer JM, Sanz F, Rello J, Marcos PJ, Velez MI, et al. Hypocapnia and hypercapnia are predictors for ICU admission and mortality in hospitalized patients with community-acquired pneumonia. Chest. 2012;142(5):1193-9.

18. Escarce JJ, Kelley MA. Admission source to the medical intensive care unit predicts hospital death independent of APACHE II score. JAMA. 1990;264(18):2389-94.

19. Youden WJ. Index for rating diagnostic tests. Cancer. 1950;3(1):32-5.

20. Salih W, Schembri S, Chalmers JD. Simplification of the IDSA/ATS criteria for severe CAP using meta-analysis and observational data. Eur Respir $\mathrm{J}$. 2014:43(3):842-51.

21. Chalmers JD, Taylor JK, Mandal P, Choudhury G, Singanayagam A, Akram AR, Hill AT. Validation of the Infectious Diseases Society of America/ American Thoratic Society minor criteria for intensive care unit admission in community-acquired pneumonia patients without major criteria or contraindications to intensive care unit care. Clin Infect Dis. 2011;53(6):503-11.

22. Ewig S, Birkner N, Strauss R, Schaefer E, Pauletzki J, Bischoff H, Schraeder P, Welte T, Hoeffken G. New perspectives on community-acquired pneumonia in 388406 patients. Results from a nationwide mandatory performance measurement programme in healthcare quality. Thorax. 2009;64(12):1062-9

23. Ehsanpoor B, Vahidi E, Seyedhosseini J, Jahanshir A. Validity of SMARTCOP score in prognosis and severity of community acquired pneumonia in the emergency department. Am J Emerg Med. 2019;37(8):1450-4.

24. Chalmers JD, Singanayagam A, Akram AR, Mandal P, Short PM, Choudhury G, Wood V, Hill AT. Severity assessment tools for predicting mortality in hospitalised patients with community-acquired pneumonia. Systematic review and meta-analysis. Thorax. 2010;65(10):878-83.

25. Loke YK, Kwok CS, Niruban A, Myint PK. Value of severity scales in predicting mortality from community-acquired pneumonia: systematic review and meta-analysis. Thorax. 2010;65(10):884-90.

26. Ewig S, Ruiz M, Mensa J, Marcos MA, Martinez JA, Arancibia F, Niederman MS, Torres A. Severe community-acquired pneumonia. Assessment of severity criteria. Am J Respir Crit Care Med. 1998;158(4):1102-8.

27. Angus DC, Marrie TJ, Obrosky DS, Clermont G, Dremsizov TT, Coley C, Fine MJ, Singer DE, Kapoor WN. Severe community-acquired pneumonia: use of intensive care services and evaluation of American and British Thoracic Society Diagnostic criteria. Am J Respir Crit Care Med. 2002;166(5):717-23.

28. Ewig S, de Roux A, Bauer T, Garcia E, Mensa J, Niederman M, Torres A. Validation of predictive rules and indices of severity for community acquired pneumonia. Thorax. 2004;59(5):421-7.

29. Renaud B, Labarere J, Coma E, Santin A, Hayon J, Gurgui M, Camus N, Roupie E, Hemery F, Herve J, et al. Risk stratification of early admission to the intensive care unit of patients with no major criteria of severe community-acquired pneumonia: development of an international prediction rule. Crit Care. 2009;13(2):R54.

30. Bauer TT, Welte T, Strauss R, Bischoff H, Richter K, Ewig S. Why do nonsurvivors from community-acquired pneumonia not receive ventilatory support? Lung. 2013;191(4):417-24.

31. Wunderink RG, Waterer $G$. Advances in the causes and management of community acquired pneumonia in adults. BMJ. 2017;358:j2471.

32. Gattarello S, Borgatta B, Solé-Violán J, Vallés J, Vidaur L, Zaragoza R, Torres A, Rello J. Decrease in mortality in severe community-acquired pneumococcal pneumonia: impact of improving antibiotic strategies (2000-2013). Chest. 2014;146(1):22-31.

33. Menendez R, Torres A, Reyes S, Zalacain R, Capelastegui A, Aspa J, Borderias L, Martin-Villasclaras JJ, Bello S, Alfageme I, et al. Initial management of pneumonia and sepsis: factors associated with improved outcome. Eur Respir J. 2012;39(1):156-62.
34. SligI WI, Asadi L, Eurich DT, Tjosvold L, Marrie TJ, Majumdar SR. Macrolides and mortality in critically ill patients with community-acquired pneumonia: a systematic review and meta-analysis. Crit Care Med. 2014;42(2):420-32.

35. Rhodes A, Evans LE, Alhazzani W, Levy MM, Antonelli M, Ferrer R, Kumar A, Sevransky JE, Sprung CL, Nunnally ME, et al. Surviving sepsis campaign: international guidelines for management of sepsis and septic shock: 2016. Intensive Care Med. 2017;43(3):304-77.

36. Ni YN, Luo J, Yu H, Liu D, Liang BM, Liang ZA. The effect of high-flow nasal cannula in reducing the mortality and the rate of endotracheal intubation when used before mechanical ventilation compared with conventional oxygen therapy and noninvasive positive pressure ventilation. A systematic review and meta-analysis. Am J Emerg Med. 2018;36(2):226-33.

37. Aliberti S, Dela Cruz CS, Amati F, Sotgiu G, Restrepo MI. Communityacquired pneumonia. Lancet. 2021;398(10303):906-19.

38. Torres A, Cilloniz C, Niederman MS, Menendez R, Chalmers JD, Wunderink RG, van der Poll T. Pneumonia. Nat Rev Dis Primers. 2021;7(1):25.

\section{Publisher's Note}

Springer Nature remains neutral with regard to jurisdictional claims in published maps and institutional affiliations.

Ready to submit your research? Choose BMC and benefit from:

- fast, convenient online submission

- thorough peer review by experienced researchers in your field

- rapid publication on acceptance

- support for research data, including large and complex data types

- gold Open Access which fosters wider collaboration and increased citations

- maximum visibility for your research: over 100M website views per year

At BMC, research is always in progress.

Learn more biomedcentral.com/submissions 